\title{
Perheväkivallan kirjaaminen terveydenhuollossa ja väkivallan vaikutukset hyvinvointiin
}

\section{VÄKIVALTA PERHEESSÄ}

Perheväkivalta on maailmanlaajuinen terveysongelma, jota esiintyy kulttuurista, yhteiskunnallisesta asemasta ja iästä riippumatta. Parisuhteessa, perheessä ja muissa läheisissä ihmissuhteissa on kautta aikojen esiintynyt fyysistä ja henkistä väkivaltaa sekä alistamista. Väkivalta on usein piilotettua ja kotona tapahtuvaa perheen sisäistä väkivaltaa. Perheväkivaltaan on havahduttu vasta 1960-luvulla ja Suomessa keskustelu aiheesta on alkanut 70-luvulla. $(1,2,3)$.

Fyysisen väkivallan, kuten lyömisen tai potkimisen, lisäksi perheväkivallan muotoja ovat psyykkinen ja seksuaalinen väkivalta. Näiden lisäksi iäkkäät vanhemmat ovat alttiita erityisesti taloudelliselle väkivallalle. Myös lasten kaltoinkohtelu on perheväkivaltaa. (4.) Parisuhdeväkivalta on yksi perheväkivallan yleisimmistä muodoista, jossa väkivallan tekijänä on puoliso tai partneri. "Puolisolla tai partnerilla" tarkoitetaan nykyistä tai entistä puolisoa, poikaystävää tai tyttöystävää. (5.)

Monet eri tekijät voivat altistaa väkivallalle ja väkivaltaa kokeneet ovat usein sekä uhreja että tekijöitä (6). Riskitekijöitä ovat lapsuudessa koettu tai nähty perheväkivalta, nuori ikä, miessukupuoli, alkoholi, heikko taloudellinen tilanne sekä koulutus, huonot suhteet vanhempiin ja kasvaminen yksinhuoltajaperheessä $(7,8,9,10)$. Varsinkin miehillä jotka ovat joutuneet näkemään ja kokemaan fyysistä väkivaltaa lapsuudessa on riski väkivallan käyttämiseen perheessään aikuisena (11).

Naiset ja miehet kokevat lähes yhtä paljon väkivaltaa tai sen uhkaa kumppaniensa taholta ja lähes kolmasosa parisuhteessa olleista on kokenut parisuhdeväkivaltaa $(12,13)$. Euroopan Unionin perusoikeusviraston tekemässä tutkimuksessa todettiin, että Suomi on EU:n toiseksi väki- valtaisin maa naisille. Lähes puolet suomalaisista naisista on kokenut fyysistä tai seksuaalista väkivaltaa 15 vuoden iästä lähtien, kun koko Euroopan laajuinen keskiarvo on joka kolmas. (14.)

Terveyden ja hyvinvoinnin laitoksen raportissa ilmeni, että vuonna 2017 Suomessa koettiin perheväkivaltaa enemmän kuin koskaan ennen tai ainakin useammat ihmiset olivat hakeneet tukea auttavasta puhelimesta tai turvakodista (15). Tämä ei välttämättä kerro "todellisesta" lisäyksestä vaan ehkä havahtumisesta, joka saattaa selittää myös sitä, että Suomi on erityisen väkivaltainen maa naisille. Viimeisimmän tilastokeskuksen raportin mukaan perheväkivallan uhreista lähes $70 \%$ oli naisia ja melkein $80 \%$ epäillyistä tekijöistä miehiä. Naisten osuus tekijöinä on kuitenkin noussut ja viidesosa väkivallasta tapahtui entisten puolisoiden välillä. (16.)

Väkivalta perheessä heikentää koko perheen hyvinvointia ja voi ulottua sukupolvien yli. Fyysisten vammojen lisäksi väkivalta heikentää psyykkistä terveyttä, kasvattaa terveyseroja ja edistää ihmisten syrjäytymistä ja eriarvoisuutta. $(17,18,19,20$. $)$ Naisilla on myös suurempi riski menehtyä perheväkivaltaan (21). Maailmanlaajuisesti lähes $40 \%$ kaikista naisten murhista tekijänä on ollut puoliso tai kumppani (13). Suomessa nykyisten tai entisten kumppaneiden aiheuttaneiden murhien uhreista $60 \%$ on naisia ja $8 \%$ miehiä (22).

Väkivalta raskauden aikana ennustaa voimakkaasti myös raskauden jälkeistä väkivaltaa. Lähes joka viides äideistä ja isistä on kokenut joko fyysistä tai henkistä väkivaltaa odotusaikana. (23.) Perheväkivalta on merkittävä riskitekijä ei-toivotulle raskaudelle, abortille ja raskauteen liittyville komplikaatioille kuten keskenmenolle, ja ennenaikaiselle synnytykselle. Väkivalta vaikuttaa myös vastasyntyneen lapsen terveyteen 
alhaisena syntymäpainona ja heikompana yleisterveytenä. $(24,25,26$.)

Myös lapset ja nuoret kärsivät perheväkivallasta ja lähes kolmasosa nuorista onkin kokenut fyysistä pahoinpitelyä kotona (27). Vanhempien keskinäinen suhde on tärkeä malli lasten omille suhteille ja heidän sosiaaliselle vuorovaikutukselle. Perheen asenteet, tottumukset ja tavat vaikuttavat siihen, kuinka ihmiset huolehtivat terveydestään, ja perheen rooli on keskeinen hyvinvoinnille. (28.) Vanhempien välinen väkivalta vaikuttaa ja vaurioittaa lasta, vaikkei se kohdistuisikaan suoraan lapseen. Väkivallan kuuleminen ja näkeminen vaarantaa heidän hyvinvointiaan ja terveyttään vähintään yhtä paljon kun muutkin väkivallan muodot. $(29,30,31$.) Suomessa lapsiin kohdistettu väkivalta on vähentynyt, mutta poikiin kohdistuva väkivalta lisääntynyt. Lapsiin kohdistuneesta väkivallasta noin kolmannes on naisten tekemää. Naisten tekemän väkivallan osuus on sitä suurempi, mitä nuorempi lapsi on uhrina. (16.)

\section{PERHEVÄKIVALTA JA SEN KIRJAAMINEN TERVEYDEN- HUOLLOSSA}

Perheväkivalta kuormittaa myös terveydenhoitoa ja yhteiskuntaa, vaikka ainoastaan murto-osa tapauksista tulee viranomaisten tietoon. Väkivaltaa kokeneet käyttävät enemmän terveydenhuollon palveluita kuin muu väestö, joten terveydenhuollon ammattilaiset ovat avainasemassa perheväkivallan tunnistamisessa ja siihen puuttumisessa. $(13,17$.

Väkivaltaa kokeneiden hoitojaksot ovat pidempiä ja hoitokulut suurempia kuin muilla potilailla keskimäärin ja heillä on useita eri diagnooseja $(32,33,34,35)$. Terveydenhuollon ammattilaisista joka kolmas on kohdannut tai hoitanut parisuhdeväkivaltaa kokeneita mies- tai naispotilaita (36).

Väkivallan aiheuttamien vammojen tutkimus on tehtävä huolellisesti ja kaikki löydökset on kirjattava potilasasiakirjoihin (37). Perheväkivallan tunnistaminen vaatii hoitohenkilökunnalta huolellista esitietojen selvittämistä sekä rohkeutta kysyä ja epäillä väkivallan mahdollisuutta (38). Yhtenäistä kirjaamiskäytäntöä ei kansainvälisesti ole, mutta suositusten mukaan Euroopan Unionin jäsenvaltioissa tulisi terveydenhuollossa kerätä tiedot ja kirjata jollain tavalla vähintään uhrin ikä ja sukupuoli, uhrin ja tekijän välinen suhde sekä väkivallan muoto (39). Lääkärin tekemä diagnosointi toteutetaan kansainvälisen ICD-10 tautiluokituksen avulla, jota Sosiaali- ja terveysministeriö velvoittaa käyttämään potilasasiakirjoissa osana kirjaamista (37).

ICD-luokitus on koodausjärjestelmä, jossa kaikki vammat tai sairaudet koodataan diagnoosikoodien avulla. Koodit kääntävät diagnoosit sanoista aakkosten mukaisiin luokkiin ja numeroituihin alaluokkiin, joka mahdollistaa tietojen helpon säilyttämisen, hakemisen ja analysoinnin (40).

Väkivallan aiheuttamat vammat ja väkivallan tekijä on kirjattava diagnoosikoodien avulla. Päädiagnoosin avulla ilmoitetaan väkivallan aiheuttama vamma, esimerkiksi

- S06.0 aivotärähdys tai

- S42.0 solisluun murtuma.

Tämän päädiagnoosin lisäksi tulisi käyttää myös lisäkoodia, joka ilmoittaa väkivallan tekijän ja tekotavan. Tekijäksi voidaan merkata eri diagnoosikoodeilla puoliso tai partneri, vanhemmat, uhrin lapsi, tuttava tai ystävä, muu tai tuntematon suorittaja. Esimerkiksi lisäkoodi....

- Y04.0 tarkoittaa Murhaa, tappoa tai muuta tahallista pahoinpitelyä ilman aseita, jonka suorittajana on puoliso tai partneri. Kun taas esimerkiksi..

- X91.0 on Murha, tappo tai muu tahallinen pahoinpitely kuristamalla suorittajana puoliso tai partneri. (41.)

Tarkka ja täsmällinen kirjaaminen ja diagnoosikoodien käyttö tarjoaa tärkeää tietoa perheväkivallan aiheuttamista vammoista ja väkivallan erityispiirteistä. Lisäksi huolellinen kirjaaminen lisää perheväkivallan havaitsemista ja ongelman näkyvyyttä yhteiskunnassa. Selkeä ja kattava esitietojen ja havaintojen kirjaaminen edesauttaa myös rikosoikeudellisen lääkärinlausunnon laatimista, jos siihen on tarvetta. Tämä lausunto sisältää tärkeän ja puolueettoman kuvauksen potilaan vammoista tuomioistuimelle, joka vaikuttaa myös potilaalle annettavaan korvaukseen ja syylliselle määrättävään tuomioon. (37.)

Valitettavasti perheväkivallan tunnistaminen ja kirjaaminen on edelleen vaikeaa ja kirjavaa terveydenhuollossa, mikä aliarvioi väkivallan esiintyvyyttä. Onkin mahdollista, että varsin suuri osa perheväkivaltatapauksista jää ilman tun- 
nistamista ja oikeaa diagnoosia, koska tapaukset ovat haasteellisia havaita ja tunnistaa. (42).

Puutteellinen ja epäyhtenäinen kirjaaminen heikentävät valtakunnallisten ja kansainvälisten tilastojen luotettavuutta ja käyttökelpoisuutta sekä vaikeuttavat hoidon seurantaa ja kehittämistä. Tunnistamisesta huolimatta diagnoosikoodeja käytetään myös liian vähän ja niiden käytössä on suuria eroja eri sairaaloiden kesken (38). Lisäksi diagnoosiluokitus kattaa ainoastaan sairaalahoitoon tulleet ja tunnistetut potilaat, jotka ovat vain jäävuoren huippu perheväkivaltatapauksista (43).

Terveydenhuollon ammattilaisten taidot tunnistaa ja puuttua perheväkivaltaan ovat kohtalaiset tai huonot ja lisää tietoa ja koulutusta aiheesta kaivataan. Tunnistamisen vaikeuden syinä ovat aiheen arkaluontoisuus, ohjeiden ja potilaan taustatietojen puute, oireiden moninaisuus, potilaiden kokema häpeä, henkilökunnan kiire ja levoton työympäristö. $(36,44,45$.)

Perheväkivaltapotilaiden hoito vaatii ammattitaitoa ja valppautta sekä monialaista yhteistyötä ja yhteisesti sovittuja toimintatapoja (46). Terveydenhuollossa potilaan täytyy tuntea olonsa turvalliseksi, jossa häntä kohdellaan kunnioittavasti ilman leimautumista ja hän voi saada hyvää ja laadukasta hoitoa ja tukea (17).

\section{VÄITÖSKIRJAN SISÄLTÖ JA TAVOITE}

Tutkin väitöskirjassani perheväkivallan kirjaamista terveydenhuollossa, sekä väkivallan yhteyttä yksilön ja koko perheen hyvinvointiin. Tutkimukseni tavoitteena on laajentaa terveydenhuollon ammattilaisten osaamista perheväkivallan monimuotoisuudesta ja sen vaikutuksista erityisesti perheiden hyvinvointiin. Perheväkivallan kirjaamista ja diagnoosikoodien käyttöä perheväkivaltapotilaiden hoidossa ei ole Suomessa kuvattu näin laajasti aikaisemmin. Lisäksi perheväkivaltaa kohdanneiden perheiden hyvinvoinnista on vain vähän tietoa.

Tutkimusaineisto sisälsi yhteensä 1561 osallistujaa. Aineisto on kerätty sairaalan sähköisistä potilasasiakirjoista sekä kyselylomakkeilla. Kirjaamisen ja sairaalahoitoon joutuneiden potilaiden aineisto $(\mathrm{N}=1302)$ on kerätty kahdessa eri vaiheessa erään suomalaisen keskussairaalan sähköisestä potilasrekisteristä valittujen ICD-10 diagnoosikoodien avulla ajalta 1.1.2008-31.12.2017. Painopisteenä on parisuhdeväkivalta ja potilas- asiakirjojen aineisto rajattiin täysi-ikäisiin sairaalahoitoon joutuneisiin potilaisiin.

Toinen aineisto kerättiin perheväkivallan yhteydestä perheen toimivuuteen, terveyteen ja saatuun tukeen FAFHES-lomakkeen (Family Functioning, Health and Social Support) avulla. Kyselylomakkeen avulla kartoitin fyysisen tai psyykkisen perheväkivallan kokemista ilman erillistä aikarajaa eli osallistujat ovat voineet kokea väkivaltaa myös lapsena. Ensimmäinen FAFHES-kysely kerättiin eräässä keskussairaalassa asioineilta potilailta 10/2012-03/2013 ja jatkokysely kerättiin ensimmäisen kyselyn vastaajilta 03/2015-09/2015.

Aineistojen analysointi toteutettiin sekä laadullisen, että tilastollisen menetelmän avulla. Potilasrekisterin potilasasiakirjat analysoitiin laadullisesti sisällön analyysillä ja FAFHES-lomakkeet tilastollisesti SPSS ohjelmalla.

\section{TULOKSET}

Aineistosta löytyi yhteensä 206 (13\%) perheväkivallan uhria tai tekijää. Suurin osa perheväkivallan uhreista oli nuoria naisia, tapahtuma-aikana yö ja väkivaltaan liittyi alkoholi. Uhreihin kohdistettiin erilaisia väkivallan tekotapoja, jotka aiheuttivat useita eri vammoja. Väkivallan yleisyys ja roolit (uhri tai tekijä) perheessä vaihtelivat tutkimuksen aikana. Perheen toimivuus oli heikkoa väkivallan kokijoilla sekä osallistujilla, joiden perheissä väkivalta oli jatkunut. Perheiden terveys oli vaihtelevaa ja naisilla hieman heikompaa kuin miehillä. Terveydenhuollon tuki oli heikompaa sekä väkivallan kokijoilla ja osallistujilla, joiden väkivalta jatkui. Väkivallan kirjaaminen ja dokumentointi osoittautui puutteelliseksi, koska ainoastaan 34 (3\%) käynneistä oli kirjattu oikean lisäkoodin avulla. Lisäkoodien määrä oli vähentynyt, vaikka merkittyjen Murha, tappo tai muu tahallinen pahoinpitely -käynnit olivat lisääntyneet.

Perheväkivalta on kliininen ja emotionaalinen haaste kaikille terveydenhuollon ammattilaisille, jotka työssään tapaavat, tutkivat ja hoitavat perheväkivallan uhreja. Väkivallan kirjaaminen osoittautui puutteelliseksi, joten siihen tulisi panostaa enemmän osana potilaan hyvää hoitoa. Lisäksi perheväkivallan uhrien ja tekijöiden, sekä heidän perheidensä kokonaisvaltaiseen hyvinvointiin tulisi kiinnittää huomiota. 
Uutta tietoa tarvitaan perheväkivaltapotilaiden ja heidän perheidensä hoidon parantamiseksi. Hyvän hoidon ja kirjaamisen avulla voidaan lisätä perheiden hyvinvointia sekä tarjota tärkeää tietoa esimerkiksi lastensuojelun tarpeisiin. Tutkimustulosteni tulisi rohkaista terveydenhuollon ammattilaisia tunnistamaan paremmin väkivalta ja puuttua siihen sekä huomioimaan laajemmin väkivallan uhrien tai tekijöiden ja heidän perheidensä fyysinen ja henkinen hyvinvointi.

Väitöskirjaan voi tutustua osoitteessa https://trepo.tuni.fi/handle/10024/118932
Terveystieteiden maisteri Salla Kivelän väitöskirja "The Documentation of Family Violence in Healthcare and the Associations of Violence on Well-Being" tarkastettiin Tampereen yliopiston Yhteiskuntatieteiden tiedekunnassa 31.1.2020. Vastaväittäjänä toimi dosentti Kaisa Haatainen Itä-Suomen yliopistosta ja kustoksena professori Eija Paavilainen Tampereen yliopistosta.

\section{Salla Kivelä}

TtT

Tampereen yliopisto, Terveystieteet

Laurea-ammattikorkeakoulu, Tikkurilan kampus

\section{LÄHTEET}

(1) Krug EG, Dahlberg LL, Mercy JA ym. Väkivalta ja terveys maailmassa WHO:n raportti. 2006. http://www.who.int/violence_injury_prevention/ violence/world_report/full_fi.pdf

(2) Oranen M (toim.) Perheväkivallan varjossa. Raportti lapsikeskeisen työn kehittämisestä. Ensi- ja turvakotien liiton julkaisu 30. Helsinki. 2001.

(3) Ruohonen M. Perhe- ja lähisuhdeväkivallan vastaisen työn kehitys Suomessa. Kirjassa: Perheja lähisuhdeväkivalta. Auttamisen käytäntöjä. Helsinki: Ensi- ja turvakotien liitto. 2006.

(4) Krug EG, Dahlberg LL, Mercy JA ym. World report on violence and health. Geneva, World Health Organization. 2002. http://apps.who.int/ iris/bitstream/10665/42495/1/9241545615_eng. pdf

(5) Breiding MJ, Basile KC, Smith SG ym. Intimate partner violence surveillance: Uniform definitions and recommended data. 2015. https://www.cdc.gov/violenceprevention/pdf/ipv/ intimatepartnerviolence.pdf

(6) Caetano R, Vaeth PAC, Ramisetty-Mikler S. Intimate Partner Violence Victim and Perpetrator Characteristics Among Couples in the United States. J Fam Violence. 2008;23(6):507-518. doi: $10.1007 / \mathrm{s} 10896-008-9178-3$

(7) Costa B, Kaestle C, Walker A ym. Longitudinal predictors of domestic violence perpetration and victimization: A systematic review. Aggress Violent Behav. 2015;24:261-272. doi: 10.1016/j.avb.2015.06.001

(8) Mavrikiou PM, Apostolidou M, Parlalis SK. Risk factors for the prevalence of domestic violence against women in Cyprus. J Soc Sci. 2014;51(2):295-301. doi: 10.1016/j.soscij.2014.02.002

(9) Ralo J, Schor N, Tavares C ym. Prevalence of family violence and associated factors among in-school adolescents in São Paulo, Brazil. J Interpers Violence. 2016;31(9):1618-1633. doi: 10.1177/0886260515569059
(10) Thornberrya T, Matsudaa M, Greenmana S ym. Adolescent risk factors for child maltreatment. Child Abuse Negl. 2014;38(4):706-722. doi: 10.1016/j.chiabu.2013.08.009

(11) Fowlera R, Cantosa AL, Miller SA. Exposure to violence, typology, and recidivism in a probation sample of domestic violence perpetrators Drew. Child Abuse Negl. 2016;59:66-77. doi: 10.1016/j.chiab.2016.07.007

(12) Reid R., Bonomi A, Rivara F ym. Intimate partner violence among men: Prevalence, chronicity, and health effects. Am J Prev Med. 2008;34(6):478-485. doi: 10.1016/j.amepre.2008.01.029

(13) World Health Organization/London School of Hygiene and Tropical Medicine and the South African Medical Research Council. Global and regional estimates of violence against women: Prevalence and health effects of intimate partner violence and nonpartner sexual violence. World Health Organization. 2013. http://apps.who.int/ iris/bitstream/10665/85239/1/9789241564625_ eng.pdf

(14) European Union Agency for Fundamental Rights. Violence against women: An EUwide survey. 2014. https://fra.europa.eu/en/ publication/2014/violence-against-women-euwidesurvey-main-results-report

(15) Terveyden ja hyvinvoinnin laitos. Lähisuhdeväkivalta 2018. Tilastoraportti 40/2018. https://thl.fi/fi/tilastot-ja-data/ tilastotaiheittain/lapset-nuoret-ja-perheet/ lahisuhdevakivalta-2017

(16) Official Statistics of Finland. Statistics on offences and coercive measures [e-publication]. ISSN=2342-9178. Helsinki: Statistics Finland. 2017. http://www.stat.fi/til/rpk/2017/15/ rpk_2017_15_2018-0531_tie_001_en.html

(17) García-Moreno C, Jansen HA, Ellsberg M ym. WHO multi-country study on women's health and domestic violence against women. Initial results on prevalence, health outcomes and women's responses. World Health Organization. 
2005. http://www.who.int/reproductivehealth/ publications/violence/24159358X/e/

(18) Hellemans S, Loeys T, Buysse A ym. Intimate partner violence victimization among nonheterosexuals: Prevalence and associations with mental and sexual well-being. J Fam Violence. 2015;30:171-188.

doi: 10.1007/s10896-015-9669-y

(19) Paranjape A, Sprauve-Holmes N, Gaughan J ym. Lifetime exposure to family violence: Implications for the health status of older African American Women. J Women's Health. 2009;18(2), 171-175.

doi: 10.1089/jwh.2008.0850

(20) World Health Organization (WHO)/London School of Hygiene and Tropical Medicine. Preventing intimate partner and sexual violence against women: Taking action and generating evidence. Geneva: World Health Organization. 2010. http://www.who.int/ violence_injury_prevention/publications/ violence/978941564007_eng.pdf

(21) Sabri B, Sanchez M, Campbell C. Motives and characteristics of domestic violence homicides and suicides among women in India. Health Care Women Int. 2015;36:851-866. doi: 10.1080/07399332.2014.971954

(22) Lehti M. Henkirikoskatsaus. Helsingin yliopisto valtiotieteellinen tiedekunta kriminologian ja oikeuspolitiikan Instituutti. Katsauksia 28/2018. https://helda.helsinki.fi/bitstream/ handle/10138/233586/Katsauksia_28_ Lehti_2018.pdf? sequence=1\&isAllowed $=y$.

(23) Pajarita C, Perreira, K. Intimate partner violence during pregnancy and 1-year post-partum. J Fam Violence. 2007;22(7):609-619. doi: 10.1007/s10896-007-9112-0

(24) Burke JG, Lee LC, O’Campo P. An exploration of maternal intimate partner violence experiences and infant general health and temperament. Matern Child Health J. 2008;12(2):172-179. doi: $10.1007 / \mathrm{s} 10995-007-0218-\mathrm{z}$

(25) Leone J, Lane S, Koumans E ym. Effects of intimate partner violence on pregnancy trauma and placental abruption. J Women's Health. 2010;19(8):1501-1509.

doi: 10.1089/jwh.2009.1716

(26) Meiksin R, Meekers D, Thompson S ym. Domestic violence, marital control, and family planning, maternal, and birth outcomes in Timor-Leste. Matern Child Health J. 2015;19(6):1338-1347. doi: 10.1007/s10995-014-1638-1

(27) Norman R, Byambaa M, Butchart A ym. The long-term health consequences of child physical abuse, emotional abuse, and neglect: A systematic review and meta-analysis. PLOS Med. 2012;9(11). doi: e1001349

(28) Cao YP, Yang SC, Wang GQ ym. Sociodemographic Characteristics of Domestic Violence in China: A Population Case-Control Study. J Interpers Violence. 2014;29(4):683-706. doi: $10.1177 / 0886260513505218$
(29) Costa B, Kaestle C, Walker A ym. (2015). Longitudinal predictors of domestic violence perpetration and victimization: A systematic review. Aggress Violent Behav. 2015;24:261272. doi: 10.1016/j.avb.2015.06.001

(30) Ellonen N, Piispa M, Peltonen K ym. Exposure to parental violence and outcomes of child psychosocial adjustment. Violence Vict. 2013:28(1):3-15 doi: 10.1891/0886-6708.28.1.3

(31) Ruddle A, Pina A, Vasquez E. Domestic violence offending behaviors: A review of the literature examining childhood exposure, implicit theories, trait aggression and anger rumination as predictive factors. Aggress Violent Behav. 2017;34:154-165. doi: 10.1016/j.avb.2017.01.016

(32) Chan K, Choi W, Fong D ym. Characteristics of family violence victims presenting to emergency departments in Hong Kong. J Emerg Med. 2013;44(1):249-258. doi: 10.1016/j.jemermed.2012.01.061

(33) Kothari C, Rhodes K. Missed opportunities: Emergency department visits by police identified victims of intimate partner violence. Ann Emerg Med. 2006;47(2):190-199.

(34) Matteoli M, Piacentino D, Kotzalidis GD $\mathrm{ym}$. The clinical and radiological examination of acute intimate partner violence injuries: A retrospective analysis of an Italian cohort of women. Violence Vict. 2016;31(1):85-102. doi: 10.1891/0886-6708.VV-D-14-00107

(35) Notko M, Holma J, Husso M ym. Lähisuhdeväkivallan tunnistaminen erikoissairaanhoidossa. Duodecim. 2011;127(15):1599-1606.

(36) Leppäkoski T, Flinck A, Paavilainen E. Assessing and enhancing health care providers' response to domestic violence. Nurs Res Pract. 2014; article ID 759682. https:// www-hindawicom.helios.uta.fi/journals/ nrp/2014/759682/

(37) Terveyden ja hyvinvoinnin laitos. Väkivallan uhrin tutkiminen ja rikosoikeudellinen lääkärinlausunto. 2016. https://thl.fi/fi/ palvelut-ja-asiointi/valtion-sosiaali-jaterveydenhuollonerityispalvelut/oikeuslaakinta/ ohjaus-ja-valvonta/ohjeita-viranomaistenjaammattilaisten-tyon-tueksi/rikosoikeudellinenlaakarinlausunto

(38) Lunetta P, Impinen A, Lounamaa, A. Underreporting of external cause codes in the Finnish Hospital Discharge Register. Scand J Public Health. 2008;36:870-874. doi: $10.1177 / 1403494808089565$

(39) Ruuskanen E, Aromaa K. Administrative data collections on domestic violence of Europe member states. European Institute for Crime Prevention and Control, affiliated with the United Nations (HEUNI). Directorate General of Human Rights and Legal Affairs, Council of Europe 2008. http://www.coe.int/t/dg2/ equality/domesticviolencecampaign/Source/EGVAWDC(2008)Study_en.pdf 
(40) World Health Organization. ICD-11: Classifying disease to map the way we live and die. 2018. http://www.who.int/healthtopics/internationalclassification-of-diseases

(41) World Health Organization. ICD-10: International statistical classification of diseases and related health problems (5th ed.) Malta: WHO Library Cataloguing-in-Publication Data. 2016.

(42) Nittis M, Hughes R, Gray C ym. Domestic violence documentation project 2012. J Forensic Leg Med. 2013;20(6):683-689. doi: 10.1016/j.jflm.2013.04.002

(43) O’Donnell M, Nassar N, Leonard H ym. Monitoring child abuse and neglect at a population level: Patterns of hospital admissions for maltreatment and assault. Child Abuse Negl. 2010;34,:823-832.

doi: 10.1016/j.chiabu.2010.04.003
(44) Bradbury-Jones C, Taylor J, Kroll T ym. Domestic abuse awareness and recognition among primary healthcare professionals and abused women: A qualitative investigation. J Clin Nurs. 2014;23(21-22):3057-3068. doi: 10.1111/jocn.12534

(45) McCauley M, Head J, Lambert J ym. Keeping family matters behind closed doors: Healthcare providers' perceptions and experiences of identifying and managing domestic violence during and after pregnancy. BMC Pregnancy Childbirth. 2017;17:318. doi: 10.1186/s12884-017-15204

(46) Leppäkoski T, Flinck A, Paavilainen E. Greater commitment to the domestic violence training is required. J Interprof Care. 2015;29(3):281-283. doi: 10.3109/13561820.2014.955913 